\title{
A Study on the Construction of a Culture Pedagogical Network Learning Space
}

\section{The CASH Curriculum Idea}

\author{
https://doi.org/10.3991/ijet.v14i17.11235 \\ Guoxin Li ${ }^{(凶)}$, Shaojuan Ouyang \\ Qinhuangdao Vocational and Technical College, Qinhuangdao, China \\ qhdlgxoysj@126.com \\ Yonghai Yang \\ Sichuan Vocational and Technical College, Suining, China
}

\begin{abstract}
The booming information technology has brought non-negligible and irreversible great influence on our production and life styles, including the education sector. At present, although the teaching mode of culture pedagogy guarantees students' overall grasp of culture pedagogy, students' learning for culture pedagogy is not deep enough, and they can neither internalize relevant knowledge nor form the cure quality of culture pedagogy. Besides, the teaching effect is not entirely satisfactory. Thus, the teaching mode which is based on CASH curriculum idea and supported by information technology combines network learning space and utilizes the patent A Method to Achieve Auxiliary Operation in PPT Courseware Playing Process, and the classroom teaching quality evaluation method based on distance comparison were proposed in this study. In addition, the modeling process of network learning space was introduced. The patent A Method to Achieve Auxiliary Operation in PPT Courseware Playing Process, standardized method of distance grade evaluation model, modeling and computer operating system, and teaching case design process of CASH curriculum idea were applied. It was found through the experiment that, students are satisfied with the teaching mode of network learning space based on CASH curriculum idea, and consider that it plays a great role in the learning process, and both the teaching efficiency and teaching quality improve obviously.
\end{abstract}

Keywords-CASH curriculum idea; network learning space; culture pedagogy

\section{Introduction}

Nowadays, the booming information technology has brought non-negligible and irreversible great influence on our production and life styles. Information technology has brought the subversive changes to many traditional industries, such as finance, traffic and retail industry. Although education sector is not completely replaced by information technology due to its features of peculiarity, variety, complexity and 
periodicity, it is also deeply influenced. National Medium and Long-term Educational Reform and Development Plan (2010-2020) clearly indicates that, information technology has the revolutionary influence on education development, so it must be valued. It is required to make the best of advantages of information technology, combine education and information technology, think the essence of education in the new era, exchange the inherent educational idea and explore how to apply the new technology.

Information technology can bring the structural reform to the educational system, promote individuation, generalization and intelligence of learning, achieve personalized customized learning, make the education free from time, place and content, and form the learning ecological system where everyone can study anytime and anywhere [1]. Besides, it can significantly improve teaching efficiency and teaching quality. The reform of education sector based on information technology is a general trend, which cannot be obstructed by individuals or organizations.

In this study, Culture Pedagogy was taken for example to explore the construction strategy of network learning space of Culture Pedagogy and the reform feasibility of information technology in the education sector based on CASH curriculum idea. In addition, network learning space and the patent A Method to Achieve Auxiliary Operation in PPT Courseware Playing Process were effectively combined to give the teaching mode reform orientation and the learning method with technical support for Culture Pedagogy in the new era, and to improve the teaching level of Culture Pedagogy.

\section{State of the Art}

CASH curriculum idea refers to creative deep integration of multiple subjects such as culture, art, society and history to cultivate students' core quality of humanistic and social science under the support of information technology. Network learning space is the web-based teaching activity and teaching management platform built under the environment of information technology. The platform can offer corresponding teaching services such as management, teaching and learning tasks for different teaching subjects such as student, parent, teacher and administrator, provide personalized learning for learners, and let learners interact with each other, storage knowledge and share knowledge. Currently, some scholars have explored CASH curriculum idea and network learning space construction. For instance, Sridharan et al. [2] studied network learning space construction strategy for middle school Chinese based on CASH curriculum idea and indicated that this mode could significantly promote students' Chinese scores and core quality. Pool [3] combined network learning space with the flipped classroom and pointed out that the mode could well optimize teaching research, learning and management. Wang et al. [4] combined network learning space with personalized learning, proposed the personalized network learning space system based on PST-SDC and found that it could obviously improve learners' learning efficiency and learning quality. Li et al. [5] combined network learning space with maker education mode, constructed the virtual network learning environment based on cloud computing center platform and supported by seven space service functions which also 
generated the positive promotion role for teaching. Zeng \& Ning [6] combined network learning space with multiple teaching modes, built the virtual community mode of mixed network teaching represented by S-ISAL teaching, adopted diverse teaching modes for different learners and greatly enhanced the learning effect. Xie \& Duan [7] based on network learning space, constructed diverse collaborative education modes, including collaborative teaching mode with assistance, collaborative teaching mode of intelligent tutor and collaborative teaching mode of virtual class, and these collaborative education modes also had the positive effects on teaching quality promotion. Bellodi \& Riguzzi [8] also combined network learning space with multiple teaching modes to solve students' doubts, and significantly improved students' learning effect.

Culture Pedagogy aims to let students know the basic category, envelopment history and current situation of culture pedagogy, understand basic concepts and opinions of culture pedagogy, grasp theoretical development trend of culture pedagogy, cognize the key and difficult points of culture pedagogy in educational practice, and form the systematic cognition system for teaching thought and theory of culture pedagogy. This course has strong theoretical property and abstraction. Hence, teachers should own solid theoretical attainment and effective teaching methods, and make the boring and abstract course vivid and concrete to stimulate students' learning interest and enthusiasm. At present, the traditional teaching method is mainly adopted for Culture Pedagogy, dominated by the teacher's explanation and students' listening. His is mainly because the teaching time of this course is limited, but there are many teaching objectives and teaching contents. To let students systematically master theoretical knowledge of culture pedagogy within the limited time, this teaching mode is appropriate. However, this teaching mode makes sure students overall and systematically grasp culture pedagogy, the resulting consequence is that students fail to deeply learn culture pedagogy, just rest on superficial knowledge, and can neither internalize relevant knowledge of culture pedagogy nor form core quality of culture pedagogy. As a result, the teaching effect is not up to expectations [9].

Based on the above defects, this study proposed to construct network learning space for Culture Pedagogy based on CASH curriculum idea. In combination of information technology, the patent A Method to Achieve Auxiliary Operation in PPT Courseware Playing Process was used to set up a brand-new teaching mode of Culture Pedagogy, and the experiment was made to probe into the practical teaching effect of this mode. The innovations of this study are as below: firstly, CASH curriculum idea is applied in culture pedagogy. The idea combines culture, art, society and history and can enhance students' core quality of culture pedagogy; secondly, network learning space is applied. Different from the traditional teaching mode, network learning space can provide a more open and flexible learning platform to meet diverse demands of different learners; thirdly, the patent A Method to Achieve Auxiliary Operation in PPT Courseware Playing Process was used to offer a more effective way to transfer knowledge for teachers, which is beneficial to improve teaching efficiency and teaching quality. In one word, the network learning space teaching mode of Culture Pedagogy based on CASH curriculum idea reflects the specific application of information technology in education. This study expects to offer the reference for corresponding information technology curriculum teaching. 


\section{Specific Ways to Construct Network Learning Space of Culture Pedagogy Based on CASH Curriculum Idea}

\subsection{Teaching application mode of network learning space}

Data mining refers to the process of discovering useful and hidden information from the massive, rich and irregular original data provided by learners [10]. Network learning space means all data of learners in the whole learning process are recorded on the virtual learning platform, and learners' cognitive style, level, learning mode and path are analyzed by data mining. Then, push service is provided for learners according to data mining results so as to achieve network learning space balance. The details are shown in Fig.1.

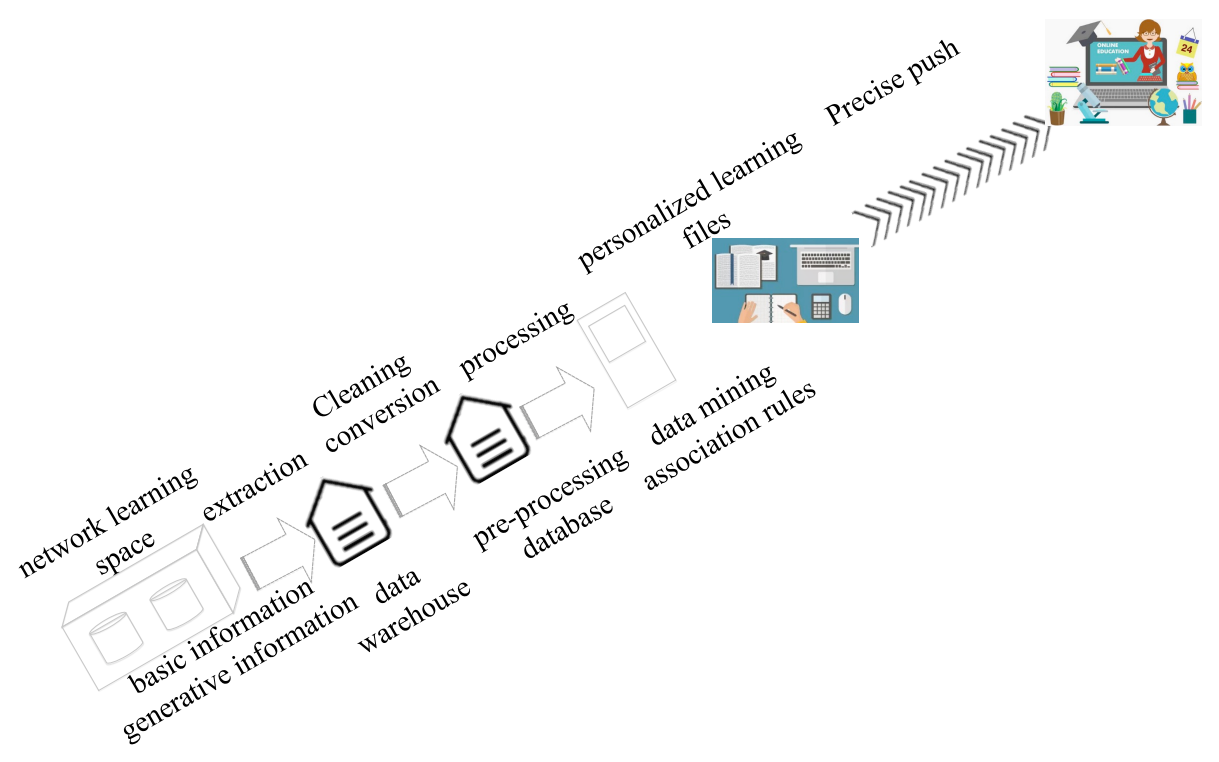

Fig. 1. Personalized push process of data mining

Knowledge aggregation means learners' scattered knowledge points are aggregated in the network learning space according to relevant relations based on learners' learning themes, knowledge network and semantic relation to form the relatively complete knowledge hierarchy [11]. Network learning space can filter useless junk information and resources so as to provide higher-level learning resources and continuously optimize network learning resources. Too enormous and complex learning resources will make learners generate cognitive load. To meet learners' personalized needs, network learning space will integrate learners' various learning resources to form the valuable system, as shown in Fig.2. 


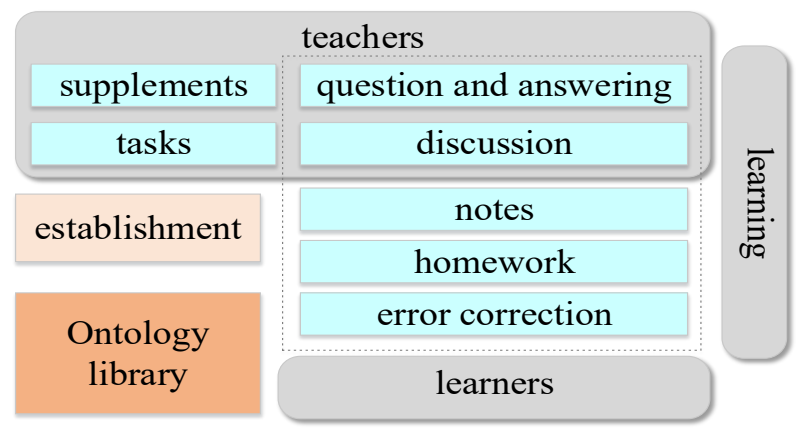

Fig. 2. Knowledge aggregation model of network learning space

\subsection{Improved PPT courseware making in network space course}

The patent A Method to Achieve Auxiliary Operation in PPT Courseware Playing Process was used to improve fluency and effect of network learning space for Culture Pedagogy. At present, the PPT courseware adopted in the teaching process often needs annotation, drawing and hyperlink to assist the explanation, but mouse movement will lead to page turning of PPT. The functions of auxiliary operations such as drawing, annotation and emphasis cannot be exerted. Besides, the teacher's teaching process will be interrupted, and teacher's teaching thought will be disturbed, thus influencing teaching fluency and reducing teaching quality. The patent A Method to Achieve Auxiliary Operation in PPT Courseware Playing Process aims to solve these problems. Based on PPT playing, a layer of transparent glass is added into the patent. Then, the picture layer is designed on the glass layer to achieve page turning on the glass layer, and other auxiliary operations such as drawing, annotation, emphasis and clearing. In this way, PPT playing quality and effect are well improved. The details are shown in Fig.3 and Fig.4.

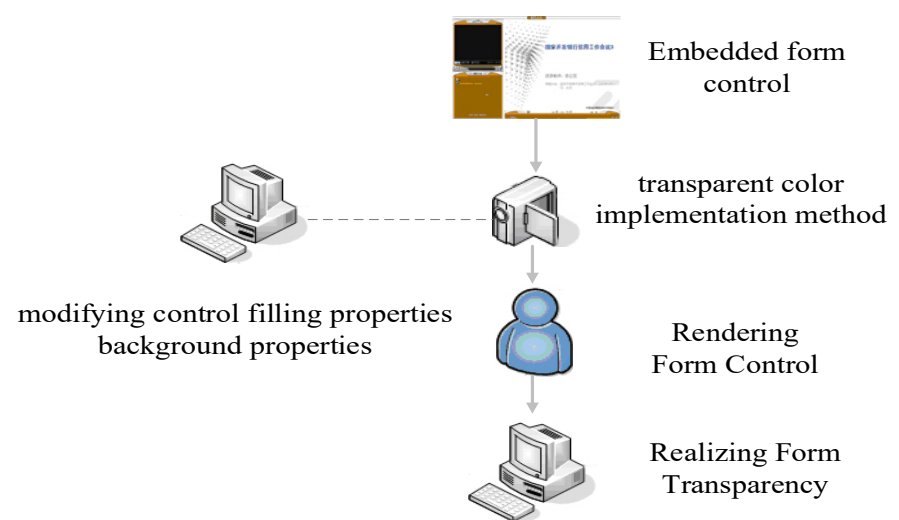

Fig. 3. The method to achieve auxiliary operations in PPT courseware playing process (1) 


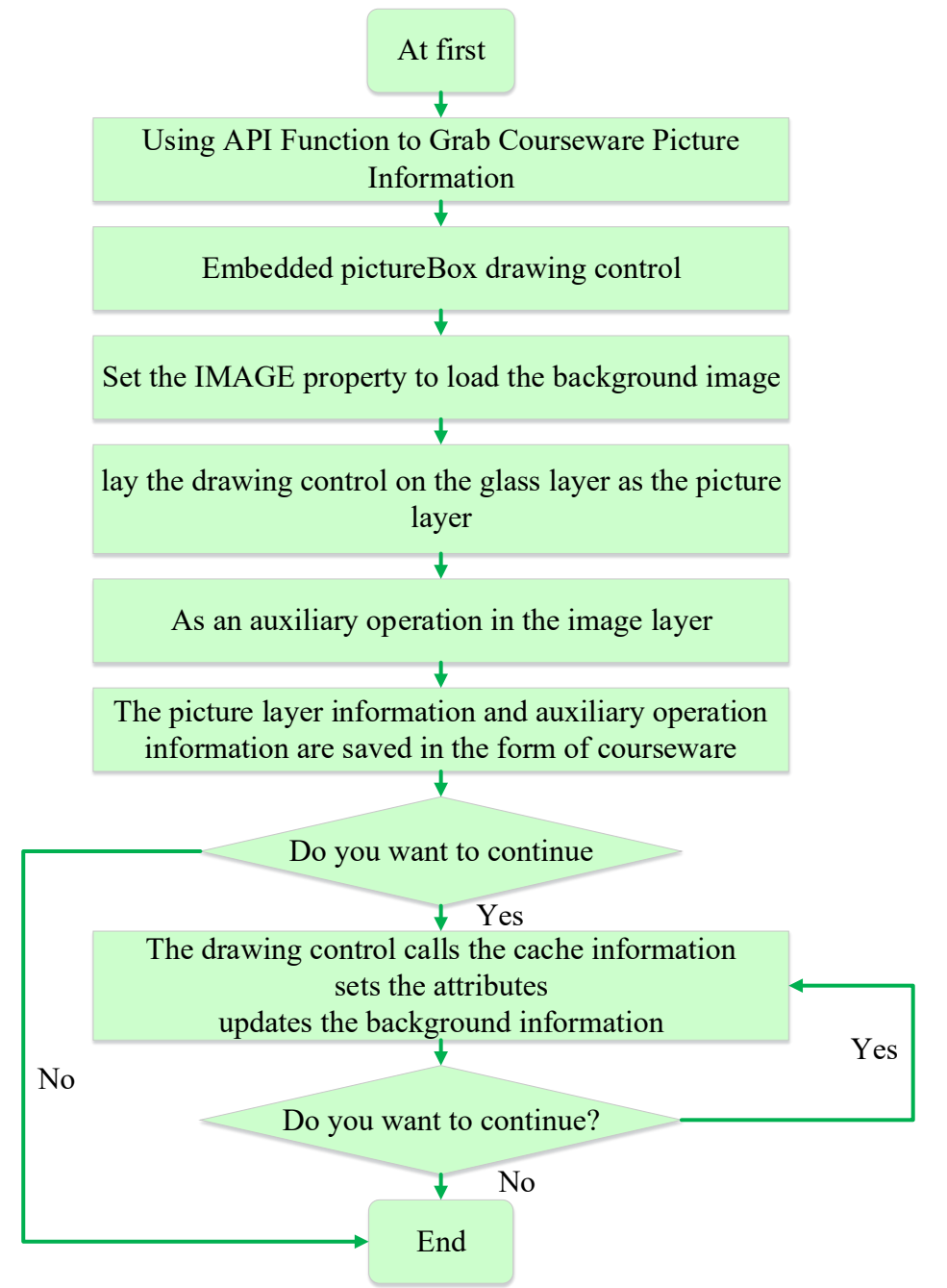

Fig. 4. The method to achieve auxiliary operations in PPT courseware playing process (2)

\subsection{Teaching design of network learning space construction based on CASH curriculum idea}

The network learning space model of Culture Pedagogy based on CASH idea is constructed by combining CASH idea, the concept and connotation of network learning space according to the standards of space balance, resource evolution and space health, as shown in Fig.5. 


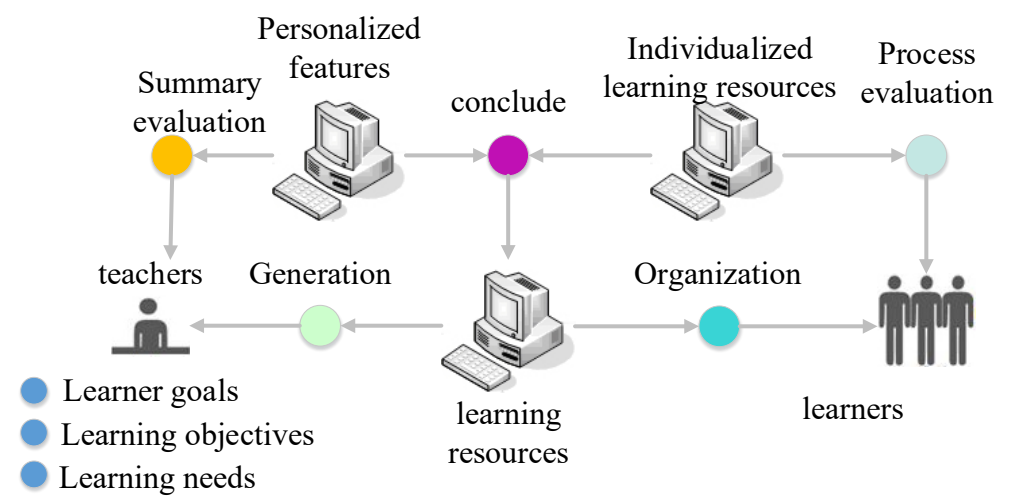

Fig. 5. Construction of network learning space for Culture Pedagogy based on CASH idea

CASH curriculum idea emphasizes that the learning process of Culture Pedagogy should contain five learning stages:

- Preview stage

- Preliminary reading stage

- Intensive reading stage

- Exploration stage

- Improvement stage

Through the network learning space of Culture Pedagogy, students can learn in any stage online, offline, in class and after class. The teacher systematically collates culture, art, society, history and other elements of Culture Pedagogy after class and offline, overall grasps and plans the textbooks of Culture Pedagogy, asks students to participate in the design and development of Culture Pedagogy, processes the collated contents artistically and uploads them to the network learning space of Culture Pedagogy for sharing. In this way, all students learning Culture Pedagogy can browse and evaluate the course to enrich the cultural connotation of Culture Pedagogy and enhance students' criticalness and creativity for the course. Generally, the general learning contents with low emotion such as basic concepts and knowledge points of Culture Pedagogy are mainly learned after class. The personalized learning contents with high emotion such as practice, criticism, evaluation and creation of Culture Pedagogy are mainly learned in class, as shown in Fig.6.

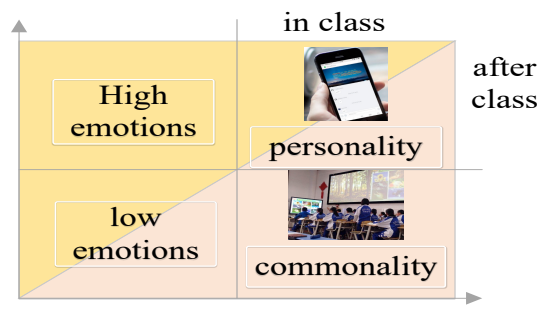

Fig. 6. Task distribution of Culture Pedagogy 


\subsection{Classroom teaching quality evaluation based on distance comparison}

Based on CASH idea and network learning space modeling, the grade evaluation model was established with the distance comparison method in the clustering analysis of multivariate statistical analysis. Besides, GUI module of MATLAB was used to build visual computer operating system of grade evaluation. Meanwhile, classroom teaching quality evaluation standard matrix was combined, and GUI operating system was used to simulate grade evaluation for classroom teaching quality of Culture Pedagogy.

Standardization method of evaluation index datamation: It is supposed that there are $m$ samples to be evaluated, and there are $n$ evaluation indexes. Every evaluation index has $\mathrm{p}$ evaluation grades. He index data matrix is $X=\left(x_{i j}\right)_{m \times n}$. The linear scale transform method is used to nondimensionalize $\mathrm{X}$. Then, the efficiency index matrix $\mathrm{A}=\left(a_{i j}\right)_{m \times n}$ can be gained, where $\mathrm{a}_{\mathrm{ij}}$ is shown in Formula 1 .

$$
a_{i j}=\left\{\begin{array}{l}
\frac{x_{i j}}{\max x_{i j}} \\
\frac{\min x_{i j}}{x_{i j}}
\end{array}\right.
$$

Similarly, for grade evaluation standard matrix $Y=\left(y_{i j}\right)_{n \times p}$, the linear scale transform method is also used to nondimensionalize $Y$. The efficiency index ma$\operatorname{trix} B=\left(b_{i j}\right)_{n \times p}$ can also be gained, where $b_{\mathrm{kt}}$ is shown in Formula 3.2.

$$
b_{i j}=\left\{\begin{array}{l}
\frac{y_{i j}}{\max y_{i j}} \\
\frac{\min y_{i j}}{y_{i j}}
\end{array}\right.
$$

Establishment of sample grade evaluation model: Step 1, calculate the Euclidean distance from each row vector in A to each column vector in $\mathrm{B}$. we can get the distance matrix $D=\left(d_{i j}\right)_{m \times p}$, where $d_{i j}$ is the distance from the $\mathrm{i}^{\text {th }}$ row of $\mathrm{A}=\left(a_{i j}\right)_{m \times n}$ (corresponding row vector after sample standardization) to the $\mathrm{j}^{\text {th }}$ column of $B=\left(b_{i j}\right)_{n \times p}$ (corresponding column vector after standardization of evaluation criterion index data), and Euclidean distance from samples after standardization o each evaluation grade, as shown in Formula (3.3).

$$
d_{i j}=\sqrt{\sum_{k=1}^{n}\left(a_{i k}-b_{i k}\right)^{2}},(i=1,2, \cdots, \mathrm{m} ; \mathrm{j}=1,2, \cdots \mathrm{p})
$$


Step 2, judge the grade of each sample and compare the distance. If $d_{i j}=\min _{1 \leq j \leq p}\left\{d_{i j}\right\}$, this means the $\mathrm{i}^{\text {th }}$ sample belongs to the $\mathrm{k}^{\text {th }}$ grade $(\mathrm{i}=1,2 \ldots, \mathrm{p})$.

GUI interface of grade evaluation mainly includes four buttons: data entry, data standardization, grade evaluation and exit.

\section{Teaching Example and Effect}

\subsection{Teaching example}

The theme "teacher" in the course of Culture Pedagogy was used for network learning space construction based on CASH idea. First of all, the teacher designed the preview questions:

- Seek the stories of famous educators or the stories of recalling teachers with deep emotion

- Seek the number of existing teachers, and the number of teacher-related songs, films and television works

- Seek teacher-related songs, play and sing them

- Seek the videos or pictures about teachers or educators, and play them

- Arrange teacher-related opuscula, songs and dances and perform them

- Narrate the feelings for the teacher occupation

- Guide students to exchange about the teacher's feelings, and how to reach the good teaching effect

- Observe the teacher's life or work details ad state

Secondly, the teacher utilized various teaching tools, such as teaching plan, electronic text and PPT and combined the preview content for learning factual and comprehensible contents. Then, communication and reading tools were used to process the course again, and culture, art, society and history elements presented in the course were collated. Besides, the teacher asked students to learn in groups, constructed the special learning space and achieved student-centered teaching. Thirdly, the network learning space was constructed, and the course of Culture Pedagogy reflecting CASH idea features was set up. Meanwhile, the criticalness and creativity of culture pedagogy improved. Fourthly, through learning "teacher" course, students could understand teachers, feel teacher's connotation, cognize teacher's life and comprehend teachers from various aspects such as language, music, film and television, drawing, body shape and interpersonal relationship.

To learn Culture Pedagogy based in CASH idea, high-level information technology is required, and five learning stages are included: preview stage, preliminary reading stage, intensive reading stage, exploration stage and improvement stage. Learners mainly learned factual and comprehensible contents after class, and conducted creative and critical learning in class. CASH idea penetrated the whole learning process, as shown in Fig.7. 
Paper-A Study on the Construction of a Culture Pedagogical Network Learning Space - The CASH ..

\begin{tabular}{|c|c|c|c|c|c|c|c|c|}
\hline $\begin{array}{l}\text { Learning } \\
\text { process }\end{array}$ & $\begin{array}{c}\text { Learning } \\
\text { process } \\
\text { Preview }\end{array}$ & & irst & tast & $\nabla$ & exploring & & sublimating \\
\hline $\begin{array}{l}\text { CASH } \\
\text { element } \\
\text { analysis }\end{array}$ & $\begin{array}{c}\text { Education } \\
\text { culture }\end{array}$ & $\begin{array}{c}\text { film } \\
\text { culture }\end{array}$ & $\begin{array}{l}\text { music } \\
\text { culture }\end{array}$ & $\begin{array}{l}\text { painting } \\
\text { culture }\end{array}$ & $\begin{array}{l}\text { social } \\
\text { culture }\end{array}$ & life culture & $\begin{array}{c}\text { regional } \\
\text { culture }\end{array}$ & $\begin{array}{l}\text { history } \\
\text { culture }\end{array}$ \\
\hline $\begin{array}{l}\text { information } \\
\text { technology }\end{array}$ & courseware & & & electronic t & hing mat & & & $\begin{array}{c}\text { CASH } \\
\text { resources }\end{array}$ \\
\hline
\end{tabular}

Fig. 7. Network learning space construction for Culture Pedagogy based on CASH idea

The course "teacher" contains abundant cultural contents. CASH elements were analyzed from such aspects as educational culture, screen culture, music culture, drawing culture, social culture, life culture, regional culture and historical culture, as shown in Table 1.

Table 1. CASH element analysis of Culture Pedagogy

\begin{tabular}{|l|l|}
\hline \multicolumn{1}{|c|}{ CASH element } & \multicolumn{1}{c|}{ Content introduction } \\
\hline Educational culture & Collate teacher's background, school, reprehensive educators and teachers, etc. \\
\hline Screen culture & $\begin{array}{l}\text { Collect teacher-related films and television works and know the contents and ex- } \\
\text { pression forms of works }\end{array}$ \\
\hline Music culture & $\begin{array}{l}\text { Gather teacher-related music works, sing and understand the emotions expressed in } \\
\text { the works }\end{array}$ \\
\hline Drawing culture & Collect teacher-related paintings and appreciate them \\
\hline Social culture & $\begin{array}{l}\text { Collect teacher-related stories, teacher's teaching modes and feelings for teachers, } \\
\text { etc. }\end{array}$ \\
\hline Life culture & Observe teacher's work and life details, and overall understand duties of teachers \\
\hline Regional culture & $\begin{array}{l}\text { Compare differences and similarities of the levels, connotations and forms of } \\
\text { teachers at home and abroad }\end{array}$ \\
\hline History culture & $\begin{array}{l}\text { Introduce historical background of teachers and education, domestic and foreign } \\
\text { current situations to help students understand }\end{array}$ \\
\hline
\end{tabular}

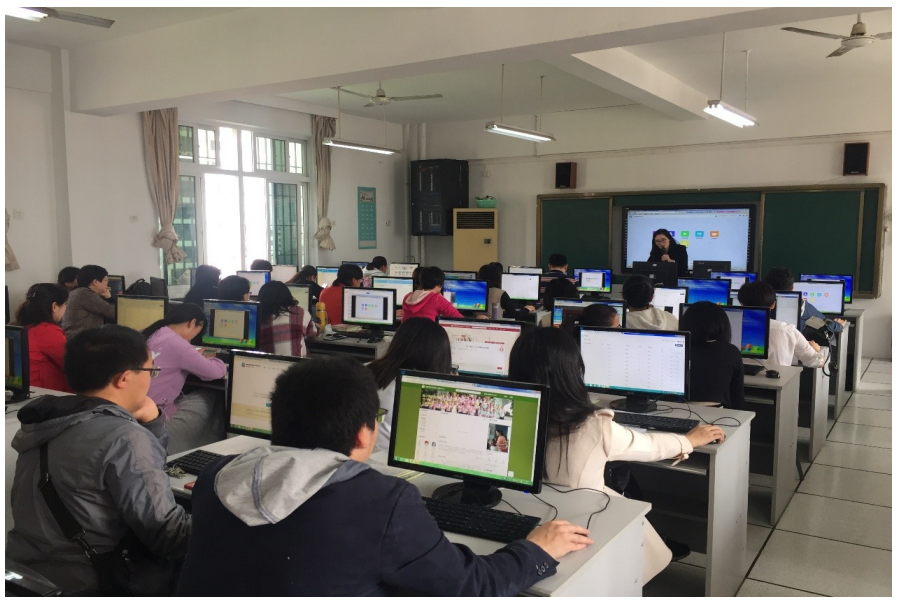

Fig. 8. Teacher-student interaction display of network learning space 


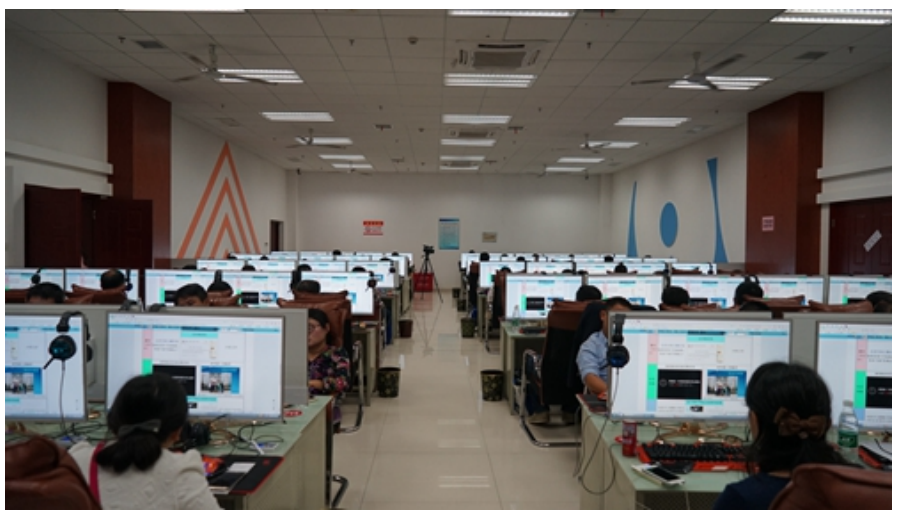

Fig. 9. Students' learning link display of network learning space

\subsection{Teaching effect}

In this study, 98 students from the college of education in a university were chosen as the objects of experiment, including 48 male students and 50 female students. The experimental curriculum was Culture Pedagogy, and the study period was the whole semester from September 2018 to December 2018. The course was taught once per week, and 2 class hours each time. The experimental group included 49 students and was taught by network learning space based on CASH idea. The control group contained 49 students, and was taught by traditional teaching method.

The questionnaire survey was employed to survey the satisfaction of both groups for Culture Pedagogy. Meanwhile, the functional evaluation of network learning space based on CASH idea was investigated for the experimental group. The results are shown in Table 2 and Table 3.

Table 2. Teaching satisfaction survey of Culture Pedagogy (No., \%)

\begin{tabular}{|l|c|c|c|c|}
\hline \multicolumn{1}{|c|}{ Group } & Very satisfied & Satisfied & General & Dissatisfied \\
\hline Experimental group & $32(65.3)$ & $12(24.5)$ & $5(10.2)$ & $0(0.0)$ \\
\hline Control group & $17(34.7)$ & $19(38.8)$ & $9(18.4)$ & $4(8.2)$ \\
\hline
\end{tabular}

It can be seen from Table 2 that, the satisfaction of experimental group for Culture Pedagogy is far higher than that of control group, fully indicating that the network learning space mode based on CASH idea proposed in this study can significantly improve teaching satisfaction for Culture Pedagogy. It can be seen from Table 3 that, all students in the experimental group think highly of network learning space mode based on CASH idea in the aspect of functions, fully demonstrating that the network learning space mode based on CASH idea can significantly improve students' learning interest in Culture Pedagogy, enhance their autonomous learning ability, promote their critical thinking ability, strengthen the interaction between students and the teacher and among students, boost teamwork spirit, and contribute to grasping key and difficult knowledge, expanding knowledge width and depth, and gaining new 
professional knowledge. Hence, this teaching mode can significantly improve teaching efficiency and teaching quality.

Table 3. Functional evaluation of network learning space for Culture Pedagogy based on CASH idea (No., \%)

\begin{tabular}{|l|c|c|c|}
\hline \multicolumn{1}{|c|}{ Evaluation index } & Agree & $\begin{array}{c}\text { Basically } \\
\text { agree }\end{array}$ & Disagree \\
\hline Network plays a great role in course study & $19(38.8)$ & $30(61.2)$ & $0(0.0)$ \\
\hline Beneficial to improve learning interest & $26(53.1)$ & $20(40.8)$ & $3(6.1)$ \\
\hline Beneficial to improve autonomous learning ability & $34(69.4)$ & $14(28.6)$ & $1(2.0)$ \\
\hline Beneficial to cultivate critical thinking & $31(63.3)$ & $15(30.6)$ & $3(6.1)$ \\
\hline Beneficial to interact between students sand the teacher & $27(55.1)$ & $20(40.8)$ & $2(4.1)$ \\
\hline Beneficial to interact among students & $35(71.4)$ & $12(24.5)$ & $2(4.1)$ \\
\hline Improve teamwork spirit & $29(59.2)$ & $19(38.8)$ & $1(2.0)$ \\
\hline Beneficial to grasp key and difficult knowledge & $27(55.1)$ & $17(34.7)$ & $5(10.2)$ \\
\hline Beneficial to expand knowledge width and depth & $30(61.2)$ & $19(38.8)$ & $0(0.0)$ \\
\hline Beneficial to gain new professional knowledge & $38(77.6)$ & $11(22.4)$ & $0(0.0)$ \\
\hline
\end{tabular}

\section{Conclusion}

A network learning space teaching mode for Culture Pedagogy which is based on CASH curriculum idea and supported by information technology was designed by combining network learning space. The experimental method and questionnaire were combined to evaluate the teaching effect, and the following conclusions were gained:

- CASH idea can display the single subject content in an interdisciplinary way. Besides, it greatly enriches students' view and resources, expands knowledge width and depth, contributes to obtaining new professional knowledge and plays a significant positive role in cultivating students' comprehensive and critical thinking.

- Network learning space can make boring and abstract knowledge of culture pedagogy become rich and concrete through information technology, and stimulate students' learning interest.

- Network learning space can make students learn anywhere and anytime through open and personalized learning mode, which improves students' autonomous learning ability.

- Network learning space enhances the interaction between the teacher and students and among students, and improves teamwork ability through offering interactive space platform. Moreover, it can help students answer questions and solve doubts and contribute to mastering key and difficult knowledge.

\section{Acknowledgement}

This work was supported in part by the Research project on major theoretical and practical problems in the social sciences of Shaanxi (2017C017), The youth fund project of the humanities and social sciences of the Ministry of Education 
(16YJCZH140) and Project funding program for basic scientific research services (HUMANITIES AND SOCIAL SCIENCES) projects in central colleges and Universities (310841170662, 310828160425).

\section{$7 \quad$ References}

[1] Wu, Y, Wang, X.Y., Wang, X.F., et al. To explore the new pattern of higher education development in the region of Beijing, Tianjin \& Hebei Province - Reflections on the study of "National Reform \& Development Program for long-term (2010-2020)". China Higher Education Research, 2010, vol. 10(8), pp. 1-7.

[2] Sridharan, B., Deng, H., Corbitt, B. Critical success factors in e-learning ecosystems: a qualitative study. Journal of Systems \& Information Technology, 2010, vol. 12(4), pp. 263-288. https://doi.org/10.1108/13287261011095798

[3] Pool, J.A. How to cash in on a pharmacy course. Journal of Pharmaceutical Sciences, 2010, vol. 11(2), pp. 120-122.

[4] Wang, W., Zhao, T., Zhong, S.C. Design and Case Study on E-learning Space Based on Flipped Classroom. Journal of Distance Education, 2014, vol. 13(3), pp. 71-77.

[5] Li, Z., Zhou, D.D., Zhong, S.C. et al. Research on Personalized Web Learning Space based on Cloud Computing. Modern Educational Technology, 2016, vol. 26(11), pp. 114-120.

[6] Zeng, M.X., Ning, X.H. Construction of "4-Field-1-Center" Maker Learning Space Model:Based on Enterprise's Innovation Process. Journal of Distance Education, 2016, vol. 34(4), pp. 25-34.

[7] Xie, Q.F., Duan, Y. Why Is Blended Learning Based on Cyber Learning Space Effective: A Case of S-ISAL Approach? E-education Research, 2017, vol. 38(6), pp. 65-70.

[8] Bellodi, E., Riguzzi, F. Structure Learning of Probabilistic Logic Programs by Searching the Clause Space. Theory \& Practice of Logic Programming, 2015, vol. 15(2), pp. 169212. https://doi.org/10.1017/s1471068413000689

[9] Jacob, E., Ruess, K. Integrating Technology and Pedagogy in a Cultural Foundations Course. Journal of Computing in Teacher Education, 2000, vol. 16(4), pp. 12-17.

[10] Ma, Y.X. On the Construction of Network Course of Cultural Quality Education in Colleges and Universities. Health Vocational Education, 2015, vol. 16(5), pp. 130-132.

[11] Chylinski, M. Cash for Comment: Participation Money as a Mechanism for Measurement, Reward, and Formative Feedback in Active Class Participation. Journal of Marketing Education, 2010, vol. 32(1), pp. 25-38. https://doi.org/10.1177/0273475309335586

\section{Authors}

Guoxinis $\mathbf{L i}$ is an associate professor in the Qinhuangdao vocational and technical college, Qinhuangdao, China (qhdlgxoysj@126.com).

Shaojuan Ouyang is an associate professor in the Qinhuangdao vocational and technical college, Qinhuangdao, China (qhdlgxoysj@126.com).

Yonghai Yang is a lecturer in the Qinhuangdao vocational and technical college, Qinhuangdao, China (qhdlgxoysj@126.com).

Article submitted 2019-07-09. Resubmitted 2019-08-02. Final acceptance 2019-08-03. Final version published as submitted by the authors. 